\title{
Perilaku Kader dalam Penemuan Suspek Tuberkulosis
}

\author{
Cadre Behavior in Tuberculosis Suspect Detection
}

\author{
Nur Fadhilah* Elmi Nuryati* Artha Duarsa** Titiek Djannatun** Restu Syamsul Hadi**
}

\author{
*Sekolah Tinggi Ilmu Kesehatan Muhammadiyah Pringsewu Lampung, **Fakultas Kedokteran Universitas \\ YARSI
}

\begin{abstract}
Abstrak
Dukungan berbagai pihak meliputi perubahan perilaku masyarakat dan pemberdayakan masyarakat sangat diharapkan untuk penanggulangan tuberkulosis (TB). Pimpinan Pusat Muhammadiyah dan 'Aisyiyah Provinsi Lampung terpanggil untuk bergerak bersama dalam program penanggulangan penyakit TB agar keberhasilan penanggulangan TB dapat tercapai. Penelitian ini bertujuan mengetahui berbagai faktor yang berhubungan dengan perilaku kader dalam menemuan suspek TB di Kabupaten Lampung Tengah. Penelitian dengan metode kuantitatif dan kualitatif ini menggunakan desain potong lintang, data primer dikumpulkan dari sampel 72 kader TB 'Aisyiyah Kabupaten Lampung Tengah. Analisis dilakukan secara univariat, bivariat dengan menggunakan metode kai kuadrat, dan multivariat dengan regresi logistik. Penelitian ini menemukan lima variabel yang meliputi pengetahuan, sikap, pelatihan, dukungan pemegang program dan motivasi yang mendukung perilaku penemuan suspek. Tiga variabel yang meliputi pendidikan, pendapatan dan pekerjaan tidak mendukung perilaku penemuan suspek. Untuk meningkatkan penemuan suspek TB disarankan untuk lebih meningkat dukungan pengelola program yang berkelanjutan.
\end{abstract}

Kata kunci: Kader, motivasi, pelatihan, penemuan suspek, pengetahuan, sikap

\footnotetext{
Abstract

The support of various parties, peoples behavior and empower communities in the implementation of TB countermeasures highly expected by Muhammadiyah Central Executive and Aisyiyah Lampung Province omit to move together in a tuberculosis prevention program for successful TB control can be achieved. This study aimed to determine the related factors of behavior cadres to detect suspected tuberculosis in Lampung districy middle. The quantitative and qualitative with study design a cross sectional was conducted using primary data on samples 72 Aisyiyah tuberculosis cadres Lampung district middle. The statistical analyses were performed by chisquare and logistic regression. The study results showed a significant five
}

variable (support program managers, knowledge of cadre, motivation of cadre, attitude of cadre, training cadre) with the discovery suspected tuberculosis cases in Lampung Province. Logistic regression analysis found a good support program holders associated with the case of suspected tuberculosis. Program holders support is the most dominant factor of the discovery of suspected tuberculosis cases. Therefore the need for tangible support over again that the findings by the cadre suspected tuberculosis increased.

Keywords: Cadre, motivation, training, case suspected detection, knowledge, attitude

\section{Pendahuluan}

Penyakit tuberkulosis $(\mathrm{TB})$ termasuk penyakit menular kronis dengan waktu pengobatan yang panjang dan jenis obat yang lebih dari satu. Oleh sebab itu, di seluruh dunia, terutama di berbagai negara yang tergolong high bourden country, jumlah kasus TB terus meningkat dengan angka kesembuhan yang tergolong rendah. Pada tahun 1993, World Health Organization (WHO) mencanangkan TB sebagai salah satu kedaruratan dunia (global emergency). ${ }^{1}$ Penderita sering terancam putus berobat selama masa penyembuhan dengan berbagai alasan, antara lain merasa sudah sehat atau faktor ekonomi. Akibatnya, pengobatan harus dulangi dari awal dengan biaya yang lebih besar serta waktu berobat yang lebih lama. Di Indonesia, strategi penanggulangan TB yang direkomendasikan WHO dan bank dunia adalah strategi Direcly Observed Treatment Shortcourse Chemo-

Alamat Korespondensi: Nur Fadhilah, STIKes Muhammadiyah Pringsewu Lampung, Jl. Makam KH Ghalib No. 112 Pringsewu Lampung 35373, Hp. 082185020775,e-mail: nurfadhilah207@yahoo.co.id 
therapy (DOTS). Strategi tersebut dilaksanakan oleh seluruh fasilitas pelayanan kesehatan dan berbagai institusi terkait. Target penanggulangan TB di lndonesia mengacu pada target global yang ditentukan oleh The Global Plan to Stop TBC dari inisiatif Stop TB Partnership dengan bantuan WHO. Indikator kinerja program meliputi angka deteksi kasus (CDR) (70\%), angka konversi $(80 \%)$, angka pengobatan $85 \%$, dan angka kesalahan (error rate) $(<5 \%) .2,3$

Pimpinan Pusat Muhammadiyah dan 'Aisyiyah terpanggil untuk bergerak bersama dalam program penanggulangan penyakit TB berbasis komunitas. Pada tahun 2003, 'Aisyiyah menjadi implementing unit (IU) Departemen Kesehatan Republik Indonesia melalui dana Global Fund AIDS, Tuberkulosis, Malaria (ATM). Bentuk kegiatan penanggulangan TB 'Aisyiyah antara lain training kader TB komunitas, pengorganisasian warga berbasis desa, penemuan suspek, Basil Tahan Asam (BTA) positif yang didiagnosis dan diobati di Unit Pelayanan Kesehatan (UPK) melalui Pengawas Minum Obat (PMO), Success Rate (SR) di UPK. Kegiatan tersebut bertujuan meningkatkan Case Detection Rate (CDR), SR, dan penurunan angka prevalensi TB BTA positif oleh kader komunitas. Di Provinsi Lampung, pimpinan wilayah 'Aisyiyah berperan dalam penanggulangan TB dengan melatih para mubaliqhot 'Aisyiyah menjadi penyuluh dalam penanggulangan TB sejak tahun 2004. Berbagai program berhasil dijalankan dengan suskes. 'Aisyiyah Provinsi Lampung ditunjuk menjadi SR community TB care dalam program Penanggulangan TB Round 8 GF ATM. Sub recipient (SR) TB Aisyiyah membawahi dua sub sub recipient (SSR) meliputi SSR 'Aisyiyah Lampung Timur dan SSR KMP Sidobinangun, dan dua implementing unit (IU) meliputi IU 'Aisyiyah Kota Metro dan IU 'Aisyiyah Lampung Tengah.4,5 Di Kabupaten Lampung Tengah, suspek TB yang ditemukan setiap kuartal melebihi dari target yang diinginkan dan angka pencapaian terus meningkat. Tujuan penelitian ini untuk mengetahui berbagai faktor yang berhubungan dengan perilaku kader dalam penemuan suspek TB di Kabupaten Lampung Tengah, meliputi pendidikan, pengetahuan, pendapatan, pekerjaan, sikap, pelatihan, motivasi dan dukungan pengelola program.

\section{Metode}

Penelitian metode kuantitatif dengan desain potong lintang ini didukung data kualitatif melalui wawancara mendalam untuk menggali informasi yang dibutuhkan. Penelitian dilaksanakan di implementing unit Kabupaten Lampung Tengah pada tahun 2013. Populasi penelitian adalah seluruh kader TB Aisyiyah di sembilan kecamatan Lampung Tengah yang berjumlah 72 responden yang seluruhnya disertakan sebagai sampel. Kriteria eksklusi adalah kader kesehatan yang tidak tergabung dalam organisasi 'Aisyiyah Kabupaten Lampung Tengah. Hubungan antara variabel penelitian dianalisis dengan kai kuadrat dan analisis multivariat regresi logistik.

\section{Hasil}

Dari delapan variabel yang diteliti, variabel pelatihan dengan kategori baik 90,3\% responden, 84,7\% kader mendapat dukungan dari pengelola program, dan $80,6 \%$ kader dengan kategori perilaku baik (Tabel 1). Variabel yang memenuhi kriteria kandidat model multivariat dengan nilai $p$ kurang dari 0,005 adalah dukungan pemegang progam, pengetahuan,sikap, motivasi, dan pelatihan (Tabel 2). Variabel yang berpengaruh paling dominan adalah dukungan pengelola dengan nilai $\mathrm{OR}=$

Tabel 1. Distribusi Karakteristik Responden

\begin{tabular}{llll}
\hline Variabel & Kategori & n & $\%$ \\
\hline Perilaku kader & Baik & 58 & 80,6 \\
\multirow{2}{*}{ Usia } & Kurang & 14 & 19,4 \\
& Tua & 37 & 48,6 \\
Pendidikan & Muda & 35 & 51,4 \\
\multirow{3}{*}{ Pengetahuan } & Tinggi & 23 & 68,1 \\
& Rendah & 49 & 38,1 \\
Pendapatan & Baik & 47 & 65,3 \\
& Kurang & 25 & 34,7 \\
Pekerjaan & $\geq$ UMR & 57 & 79,2 \\
\multirow{2}{*}{ Sikap } & $<$ UMR & 15 & 20,8 \\
\multirow{2}{*}{ Pelatihan } & Bekerja & 59 & 81,9 \\
& Tidak bekerja & 13 & 18,1 \\
Motivasi & Baik & 35 & 48.6 \\
& Kurang & 37 & 51,4 \\
Dukungan & Baik & 65 & 90,3 \\
& Kurang & 7 & 9,7 \\
& Baik & 42 & 58,3 \\
& Kurang & 30 & 41,7 \\
& Mendukung & 61 & 84,7 \\
& Tidak mendukung & 11 & 15,3 \\
\hline
\end{tabular}

Tabel 2. Analisis Bivariat Faktor-faktor yang Berhubungan dengan Penemuan Supek TB

\begin{tabular}{|c|c|c|c|c|}
\hline \multirow{2}{*}{ Variabel } & \multirow{2}{*}{ Kategori } & \multicolumn{2}{|c|}{ Perilaku (\%) } & \multirow{2}{*}{ Nilai $p$} \\
\hline & & Baik & Kurang & \\
\hline \multirow[t]{2}{*}{ Pendidikan } & Tinggi & 78,3 & 21,7 & 0,986 \\
\hline & Rendah & 81,6 & 18,4 & \\
\hline \multirow[t]{2}{*}{ Pengetahuan } & Baik & 72,3 & 27,7 & $0,026^{*}$ \\
\hline & Kurang & 9,0 & 4,0 & \\
\hline \multirow[t]{2}{*}{ Pendapatan } & $\geq$ UMR & 86,0 & 14,0 & $0,058^{*}$ \\
\hline & $<$ UMR & 60,0 & 40,0 & \\
\hline \multirow[t]{2}{*}{ Pekerjaan } & Bekerja & 83,1 & 16,9 & 0,264 \\
\hline & Tidak bekerja & 69,2 & 30,8 & \\
\hline \multirow[t]{2}{*}{ Sikap } & Baik & 91,4 & 8,6 & $0,036 *$ \\
\hline & Kurang & 70,3 & 29,7 & \\
\hline \multirow[t]{2}{*}{ Pelatihan } & Baik & 88,9 & 11,1 & $0,046^{*}$ \\
\hline & Kurang & 66,7 & 33,3 & \\
\hline \multirow[t]{2}{*}{ Motivasi } & Baik & 88,0 & 12,6 & 0,037 * \\
\hline & Kurang & 63,0 & 36,4 & \\
\hline \multirow[t]{2}{*}{ Dukungan } & Mendukung & 86,9 & 13,1 & $0,005^{*}$ \\
\hline & Tidak mendukung & 45,5 & 54,5 & \\
\hline
\end{tabular}

Keterangan : *)Signifikan 
Tabel 3. Model Akhir Analisi Regresi Logistik

\begin{tabular}{lcclc}
\hline Variabel & $\mathbf{B}$ & Nilai p & OR & $\mathbf{9 5 \%} \mathbf{C I}$ \\
\hline Pendidikan & $-1,030$ & 0,273 & 0,36 & $0,06-2,25$ \\
Pengetahuan & $-1,855$ & 0,135 & 0,16 & $0,01-1,78$ \\
Pendapatan & $-1,060$ & 0,245 & 0,35 & $0,06-2,07$ \\
Pekerjaan & 0,510 & 0,616 & 1,67 & $0,23-12,20$ \\
Sikap & 1,792 & 0,073 & 6,00 & $0,85-42,65$ \\
Pelatihan & 1,003 & 0,268 & 2,28 & $0,46-16,06$ \\
Motivasi & 1,062 & 0,251 & 2,89 & $0,47-17,72$ \\
Dukungan pengelola & 2,793 & 0,009 & 16,33 & $2,00-133,48$
\end{tabular}

16,33, nilai $\mathrm{p}=0,009$, dan $95 \%$ CI OR $=2,00-133,48$ (Tabel 3).

\section{Pembahasan}

Secara umum tingkat pengetahuan responden yang tergolong baik menunjukkan tingkat pemahaman responden menerima informasi yang baik. Sikap responden dengan kategori baik 48,6\% dan kurang 51,4\% mengindikasikan sikap responden yang tidak berbeda secara signifikan. Pelatihan dengan kategori baik, sebagian responden mengikuti pelatihan lebih dari empat kali, membuktikan bahwa kegiatan pelatihan yang diselenggarakan program TB dapat diikuti responden. Motivasi yang sebagian besar tergolong baik menjadi bekal kekuatan dalam penemuan penderita suspek TB. Sebagian besar pemegang program dapat memfasilitasi berbagai permasalahan yang ditemukan responden selama kegiatan penjaringan suspek. Penelitian ini menemukan perilaku penemuan suspek TB oleh kader tergolong baik $(80,6 \%)$ yang diukur dengan kemampuan responden mengajukan pertanyaan untuk mengidentifikasi supek TB. Penelitian ini sama dengan penelitan sebelumnya tentang faktor yang memengaruhi perilaku pemegang program TB dalam penemuan suspek. ${ }^{5}$ Perilaku penemuan suspek oleh kader yang baik dapat disebabkan oleh pengetahuan, sikap, pelatihan, motivasi, dan dukungan pengelola program.

Dukungan pemegang program adalah upaya pengelola program mendukung penemuan penderita suspek TB oleh kader. Kader yang mendapat dukungan tersebut berperilaku tergolong baik $(86,9 \%)$, sedangkan yang tidak mendapat dukungan, perilaku tergolong kurang $(54,5 \%)$. Hampir semua pengelola program memberikan informasi terbaru tentang program TB, keterlibatan kader telah dimulai sejak penyusunan perencanaan dan apabila kader menemui kendala dilapangan, mereka selalu membahas dan mencarikan solusi terhadap berbagai permasalahan dan kendala yang ditemukan selama pendampingan. Pasien difasilitasi sehingga kader merasa mendapatkan bantuan semangat, penerimaan, dan caring.

Penemuan suspek yang baik juga disebabkan oleh kemampuan kader memahami informasi yang berhubung- an dengan program TB. Kader yang berpengetahuan baik berperilaku penemuan suspek yang baik (72,3\%), tetapi kader dengan tingkat pengetahuan kurang akan berperilaku penemuan suspek pun kurang $(4,0 \%)$. Penelitian sebelumnya, menemukan hubungan yang signifikan antara tingkat pengetahuan dengan CDR Program P2TB Puskesmas. Beberapa faktor yang berhubungan dengan perilaku antara lain adalah tingkat pengetahuan yang dimiliki. ${ }^{6}$ Penelitian di Kabupaten Blora, membuktikan hubungan yang bermakna antara pengetahuan dan praktik penemuan suspek TB paru. ${ }^{7}$ Pengetahuan merupakan komponen penting dan berpengaruh langsung dalam peningkatan kinerja. ${ }^{7}$ Pengetahuan diperlukan untuk membantu tindakan yang menghasilkan kinerja. ${ }^{8}$ Pengetahuan kader 'Aisyiyah didapat dari pelatihan yang diselenggarakan oleh program TB. Sesuai komitmen 'Aisyiyah, peran Muhammadiyah -'Aisyiyah dalam Program Penanggulangan TB Community TB Care adalah meningkatkan kesadaran warga untuk berpartisipasi aktif membantu pemerintah dalam menanggulangi pemberantasan penyakit TB dengan strategi DOTS di semua UPK Aisyiyah serta peningkatan pemahaman para stakeholder. ${ }^{9}$

Perilaku penemuan suspek yang baik juga disebabkan oleh sikap kader, dengan sikap yang baik perilaku penemuan suspek juga tergolong baik $(91,4 \%)$. Sebaliknya, kader dengan sikap yang kurang berperilaku penemuan suspek yang tergolong rendah $(29,7 \%)$. Sikap adalah pernyataan evaluatif yang menyenangkan ataupun yang tidak menyenangkan atau penilaian tentang objek manusia atau peristiwa. Sikap belum merupakan tindakan atau aktivitas, tetapi merupakan predisposisi tindakan perilaku. ${ }^{10}$ Sikap yang terbentuk diorganisasi membuat kader 'Aisyiyah semakin merasa penting berada di tengahtengah masyarakat yang membutuhkan. Penelitian sebelumnya menemukan hubungan yang signifikan antara sikap dengan aktivitas kader kesehatan. Sikap yang baik berpeluang untuk aktif dalam pengendalian kasus delapan kali lebih besar daripada sikap kurang. ${ }^{11}$ Organisasi wanita yang bergerak di bidang keagamaan dan kemasyarakatan, diharapkan mampu menunjukkan komitmen dan kiprah bidang kesehatan untuk membantu meningkatkan kesehatan masyarakat dan berusaha optimal di wilayahnya. Tanpa peran masyarakat yang baik, penanggulangan TB sulit dilaksanakan. Kader 'Aisyiyah mampu menjangkau suspek menemukan BTA sampai akar rumput, bahkan sampai dengan pendampingan pasien minum obat. ${ }^{12}$

Sosialisasi tentang TB dalam bentuk pelatihan yang dilakukan ternyata mampu memberikan daya ungkit terhadap pencapai suspek. Ketepatan kader menemukan suspek merupakan indikator tingkat pemahaman kader terhadap program sehingga berbagai informasi yang diperoleh melalui pelatihan berdampak terhadap tingkat pengetahuan kader tentang penanggulangan TB. Berda- 
sarkan informasi yang didapat dari kader, cukup banyak manfaat pelatihan yang mereka dapatkan, antara lain menambah pengetahuan tentang penyakit $\mathrm{TB}$, dari yang sebelumnya tidak tahu sama sekali menjadi tahu, menambah pengalaman dan dapat menjadi bekal dalam penemuan kasus TB. Sebagian besar kader Aisyiyah di Kecamatan Kalirejo mempunyai tingkat pendidikan yang rendah, tetapi melalui pelatihan hampir semua kader pernah menemukan kasus suspek. Pelatihan akan membuat mereka terampil, tanggap, dan cekatan dalam menentukan tindakan yang harus diambil karena sudah dibekali ilmu. Peningkatan pengetahuan tidak hanya diperoleh dari pendidikan formal, tetapi dapat melalui berbagai pelatihan khusus.

Kader yang memiliki motivasi tinggi dan rendah tidak jauh berbeda, semakin tinggi motivasi kader seharusnya semakin besar angka penemuan kasus TB BTA (+). Hampir semua kader pernah menemukan kasus suspek, tetapi tidak banyak yang menemukan kasus TB BTA (+). Motivasi kader yang paling mendasar menganggap kegiatan tersebut sebagai media berdakwah. Salah satu misi community TB Care adalah melaksanakan dakwah bil hak dengan mewujudkan masyarakat yang berperilaku hidup bersih dan sehat serta memanfaatkan pelayanan kesehatan yang bermutu. ${ }^{12}$

Motivasi berhubungan dengan perilaku penemuan suspek TB, motivasi yang tinggi berdampak terhadap perilaku penemuan suspek yang baik $(63,5 \%)$ sebaliknya dengan motivasi yang rendah berdampak terhadap perilaku penemuan suspek yang kurang $(36,4 \%)$. Motivasi merupakan komponen psikologis yang berefek terhadap kinerja individu. Motivasi timbul apabila diberi kesempatan dan mendapatkan umpan balik dari hasil yang diberikan. Motivasi terbangun dari kesadaran kader untuk membantu masyarakat mengidentifikasi penemuan suspek yang didasarkan pada pekerjaan sosial atau kemanusiaan. Namun, diperlukan incentive untuk meningkatkan motivasi kader. Berbagai rangsangan positif tersebut antara lain hadiah, pengakuan, promosi atau melibatkan kader pada kegiatan yang lebih luas. ${ }^{13}$

\section{Kesimpulan}

Berbagai variabel yang berhubungan dengan perilaku kader dalam penemuan suspek TB adalah dukungan pemegang program, sikap, pengetahuan, pelatihan dan motivasi. Variabel yang paling dominan adalah dukungan pemegang program.

\section{Saran}

Perlu peningkatan pendidikan nonformal kepada kader 'Aisyiyah dalam pelatihan yang berkesinambungan sehingga lebih meningkatkan pengetahuan para kader dalam membantu menemukan suspek TB. Selain itu, perlu dilakukan peningkatan reward yang tidak harus dalam bentuk uang, tetapi berupa penghargaan yang lain.

\section{Daftar Pustaka}

1. Kementerian Kesehatan. Pedoman Nasiaonal Pengendalian Tuberkulosis. Jakarta: Direktorat Jendral Pengendalian Penyakit dan Penyehatan Lingkungan; 2011.

2. Departemen Kesehatan Republik Indonesia. Pedoman Nasional Penanggulangan Tuberkulosis. Jakarta: Direktorat Jendral Pengendalian Penyakit dan Penyehatan Lingkungan; 2006.

3. Kementerian Kesehatan RI. Modul pelatihan penanggulangan tuberkulosis bagi petugas TB di sarana pelayanan kesehatan (SPK). Jakarta: Direktorat Jendral Pengendalian Penyakit dan Penyehatan Lingkungan; 2009.

4. Aisyiyah Provinsi Lampung. Sub Recipient (SR) Community TB Care. Bandar Lampung: Yayasan Aisyiyah; 2012.

5. Aisyiyah Kabupaten Lampung Tengah. Sub recipient (SR) community TB care. Lampung: Yayasan Aisyiyah; 2012.

6. Widjanarko B, Prabamurti PN, Widayat E. Pengaruh karakteristik, pengetahuan dan sikap petugas pemegang program tuberkulosis paru puskesmas terhadap penemuan suspek TB Paru di Kabupaten Blora. Jurnal Promosi Kesehatan Indonesia. 2006; 1(1): 41-52.

7. Yaslis I. Teori Perilaku dan Penelitian Kinerja. Jakarta: FKM UI; 2001

8. Departemen Kesehatan RI. Modul Pelatihan Strategi DOTS Program P2TB Paru untuk Petugas Kabupaten. Jakarta: Direktorat Jendral Pengendalian Penyakit dan Penyehatan Lingkungan; 2009

9. Murti B, Wijaya I, Suriyasa P. Hubungan pengetahuan, sikap dan motivasi kader kesehatan dengan aktifitas dalam pengendalian TB di Kabupaten Buleleng. Jurnal Magister Kedokteran Keluarga. 2013; 1 (1)

10. Presiden Republik Indonesia. Undang-undang Republik Indonesia Tahun 2003 tentang sistem pendidikan nasional. Jakarta: Sekretariat Negara Republik Indonesia; 2003.

11. Wijono S. Psikologi industri dan organisasi. Jakarta: Kencana Prenada Media Group; 2010

12. Saefullah. Peran Aisyiyah dalam penanggulangan TB sangat membanggakan. 2013 (diakses tanggal 23 Juli 2013). Diunduh dalam: http://Peran $\% 20 \%$ E2\%80\%98Aisyiyah\%20dalam $\% 20$ Penanggulanga n $\% 20$ T B $\% 20 \mathrm{~S}$ ang a t \% $20 \mathrm{Mem}$ bang ga k a $\% 27 \% 20$ $\%$ 20Islampos.htmD.

13. Notoatmodjo S. Promosi kesehatan dan ilmu perilaku. Jakarta: Rineka Cipta; 2010. 